\title{
Rancang Bangun Company Profile Kebab Ben's Berbasis Web Menggunakan Framework Codeigniter
}

\author{
Rahmat Gunawan $^{\mathrm{a} *}$ Yudiana $^{\mathrm{b}}$, Wira Yudha Apriansyah ${ }^{\mathrm{c}}$ \\ ${ }_{a, b, c}$ STMIK Rosma, Jl. Kertabumi No. 62, Karawang 41311, Indonesia \\ *Corresponding author: $\underline{\text { rahmat@rosma.ac.id }}$
}

\begin{abstract}
Website is a portal that can be accessed via the internet anytime, anywhere. One type of website is a company profile, which is an information system that can be run on various computer devices. This study aims to create a website-ba sed Kebab Ben's company profile as a means and media to promote the products in Kebab Ben's and to overcome difficulties in finding new customers. The research method used in this research is Design science research methodology (DSRM). The final result of this research is a Web Company Profile that can be used as an asset or store image.
\end{abstract}

Keywords : Company Profile, DSRMl, Web

\begin{abstract}
Abstrak
Website adalah portal yang dapat diakses melalui internet kapan saja, dimana saja. Salah satu jenis website adalah company profile, yaitu suatu sistem informasi yang dapat dijalankan di berbagai peran gkat komputer. Penelitian ini bertujuan untuk membuat company profile Kebab Ben's berbasis website sebagai sarana dan media untuk mempromosikan produk yang ada pada Kebab Ben's serya untuk mengatasi kesulitan dalam mencari pelanggan baru. Metode penelitian yang digunakan dalam penelitian ini adalah Design science research methodology (DSRM). Hasil akhir dari penelitian ini berupa Web Company Profile yang dapat digunakan sebagai aset atau citra toko.
\end{abstract}

Kata Kunci : Company Profile, DSRM, Web

\section{Pendahuluan}

Di era modern saat ini kehidupan manusia semakin maju dan berkembang, terlebih pada teknologi informasinya yang bergerak begitu cepat ke berbagai macam bidang (Kristia Akmal \& Jaenudin, 2018). Salah satu perkembangan tersebut adalah pada media promosi. Promosi adalah salah satu bagian dari bauran pemasaran perusahaan, yang isinya memberikan informasi kepada masyarakat atau konsumen tentang produk atau jasa yang ditawarkan perusahaan. Tidak hanya itu, kegiatan promosi merupakan kegiatan komunikasi antara perusahaan dengan pelanggan atau konsumen (Anggriana et al., 2017). Promosi juga dapat menjadi penentuan sebuah keberhasilan program perusahaan supaya dapat berjalan dengan lancar. Salah satu promosi yang dapat dilakukan oleh sebuah perusahaan yaitu membuat company profile. Karena company profile merupakan ringkasan deskripsi informasi tentang sebuah perusahaan dimana perusahaan dapat memilih informasi yang mau disampaikan kepada publik sesuai tujuan (Suwarno \& Sanjaya, 2020).

Company profile merupakan pencitraan dari profesionalitas sebuah perusahaan yang dapat digunakan sebagai marketing tool yang efektif karena terdapat unsur visual berupa gambar dan teks, terlebih lagi jika ditambahkan unsur multimedia yang lain akan membuat desain company profile terlihat lebih menarik dan dapat membuat pelanggan tertarik terhadap produk yang ditawarkan. Oleh karena itu, Kebab Ben's membutukan sebuah website company profile untuk mempromosikan produk mereka kepada pelanggan. 
Kebab Ben's merupakan salah satu kedai makanan yang ada di kota Karawang yang menjual berbagai varian kebab. Saat ini Kebab Ben's sudah memiliki 3 cabang yang tersebar di kota Karawang. Namun, kegiatan promosi yang ada pada kedai tersebut dinilai masih kurang, karena hanya mempromosikan produknya dengan cara memposting menu melalui media sosial, sehingga kurang menarik daya minat calon pelanggan.

Beberapa penelitian terdahulu telah berhasil merancang company profile untuk mempromosikan suatu produk seperti yang dilakukan oleh (Kristia Akmal \& Jaenudin, 2018), (Suwarno \& Sanjaya, 2020) dan (Herman \& Janah, 2020). Untuk itu penulis menawarkan dengan membangun sebuah website company profile yang dinamis dan menarik sebagai sarana untuk membantu kegiatan promosi, sehingga pemberian informasi lebih cepat dan dapat menjangkau pasar yang lebih luas serta memperkuat daya tarik Kebab Ben's.

\section{Tinjauan Pustaka}

\subsection{Rancang Bangun}

Perancangan merupakan salah satu hal yang penting dalam membuat program. Adapun tujuan dari perancangan ialah untuk memberi gambaran yang jelas lengkap kepada pemrogram dan ahli teknik yang terlibat. Perancangan harus berguna dan mudah dipahami sehingga mudah digunakan (Hasyim et al., 2014). Perancangan adalah Sebuah Proses untuk mendefinisikan sesuatu yang akan dikerjakan dengan menggunakan teknik yang bervariasi serta di dalamnya melibatkan deskripsi mengenai arsitektur serta detail komponen dan juga keterbatasan yang akan dialami dalam proses pengerjaanya (Hid ayat \& Faisal, 2019).

\subsection{Penjualan}

Penjualan dapat didefinisikan sebagai kegiatan pelengkap/suplemen dari pembelian untuk memungkinkan terjadinya transaksi yang terdiri dari serangkaian kegiatan meliputi penciptaan permintaan, menemukan si pembeli negosiasi harga dan surat pembayaran (Neisia et al., 2018). Penjualan adalah suatu proses berpindahnya suatu hak atas barang atau jasa untuk mendapatkan sumber daya lainnya seperti kas atau janji untuk membayar sesuai dengan harga yang telah disepakati saat perusahaan menjual barang dagan gannya maka akan mendapatkan hasil pendapatannya. Jumlah yang dibebankan kepada pembeli untuk dagang yang diserahkan merupakan pendapatan perusahaan yang bersangkutan (Munandar \& Suryadi, 2020).

\subsection{Web}

World Wide Web (WWW) atau sering disebut Web merupakan salah satu sumber daya internet yang berkembang pesat. Informasi Web didistribusikan dengan pendekatan hyperlink yang memungkinkan seseorang memeperoleh informasi dengan meloncat dari satu halaman ke halaman lain (Juliany et al., 2018). Website merupakan sebuah komponen yang terdiri dari teks, gambar, suara animasi sehingga menjadi media informasi yang menarik untuk dikunjungi oleh orang lain maka dari makna itu, bisa kita fahami bahwa definisi website secara sederhana adalah informasi apa saja yang bisa diakses dengan menggunakan koneksi jaringan internet (Zufria \& Azhari, 2017).

\section{5. $H T M L$}

HTML singkatan dari Hyper Text Markup Language, dokumen HTML adalah file teks murni yang dapat dibuat dengan editor text sembarang. Dokumen ini dikenal sebagai webpage. Dokumen HTML merupakan dokumen yang disajikan dalam browser web server. Dokumen ini umumnya berisi informasi ataupun interface aplikasi di dalam internet (Tisnawati \& Baharuddin, 2016).

\section{$2.6 \quad C S S$}

Menurut Kadir (2013), CSS adalah kode yang ditujukan untuk mengatur tampilan halaman web (Tisn awati \& Baharuddin, 2016). Sedangkan menurut Khafidli, CSS (Cascading Style Sheet) merupak an salah satu bahasa pemrograman web yang berguna untuk mengendalikan beberapa elemen dalam sebuah web sehingga lebih terstruktur dan seragam (Tabrani \& Pudjiarti, 2017).

\section{$2.7 \quad M y S Q L$}

Menurut Menurut Kadir (2013), MySQL tergolong sebagai DBMS (DataBase Management System). 
Perangkat lunak ini bermanfaat untuk mengelola data (Yusti, 2016).

Menurut Raharjo (2011) Hypertext Preprocessor atau yang biasa disebut dengan PHP adalah bahasa pemrograman script yang paling banyak dipakai saat ini. PHP banyak dipakai untuk memrogram situs web dinamis, walaupun tidak tertutup kemungkinan untuk digunakan untuk pemakaian lain. PHP merupakan bahasa yang hanya dapat berjalan pada server yang hasilnya dapat ditampilkan pada klien. $P H P$ telah diciptakan terutama untuk kegunaan web dan boleh menghubungkan query database (Tendra et al., 2018).

\section{Metode}

Metode penelitian yang digunakan adalah Design science research methodology (DSRM). DSRM ini mengacu pada Ken Peffers et al. DSRM menyajikan penggabungan dari prosedur, prinsip, dan praktik. Penggabungan ini diperlukan untuk menjalankan penulisan dan memenuhi tiga tujuan tersebut secara konsisten dengan melakukan proses literatur. DSRM menyediakan model proses nominal untuk melakukan penulisan DSRM, dan men yediak an model mental untuk menyajikan dan mengevaluasi penulisan. Proses DSRM mencakup enam langkah: identifikasi masalah dan motivasi, definisi tujuan untuk solusi, desain dan pengembangan, demonstrasi, evaluasi, dan komunikasi (Fernando et al., 2020). Berikut DSRM yang dapat dilihat pada gambar dibawah ini.

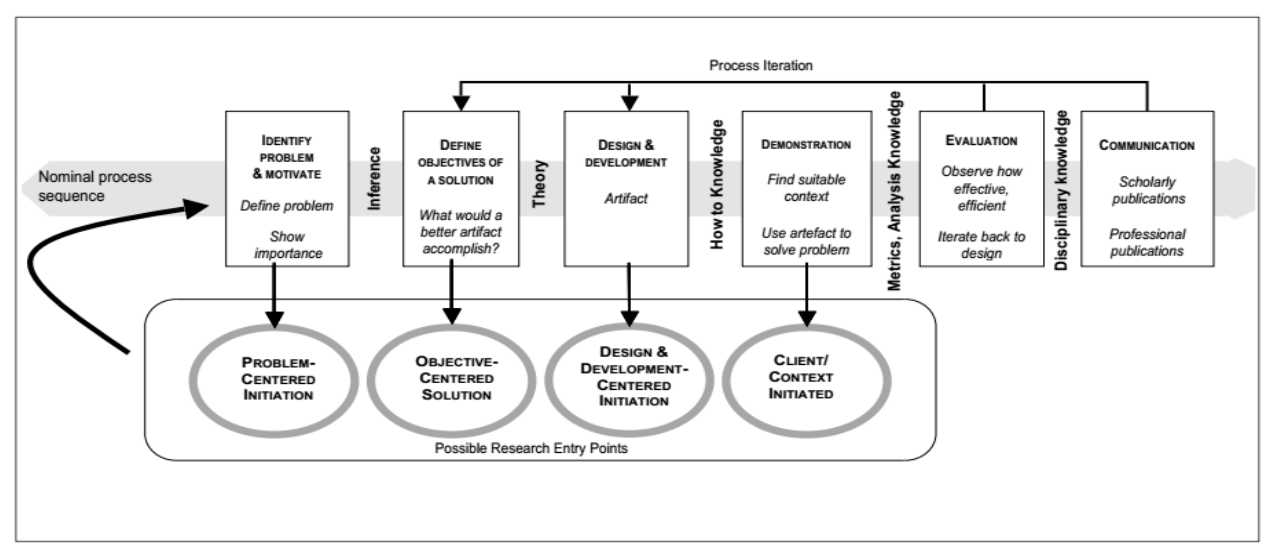

Gambar 1. Tahapan DSRM

\section{a. Problem Identification and Motivation}

Menentukan masalah didalam penulisan dan juga memberikan solusinya. Dalam proses peny ele saian masalah dengan mengembangkan sebuah artefak yang efektif dan memberikan solusi, mungkin akan berguna untuk memisahkan masalah yang konseptual sehingga mendapatkan solusi yang komplek.

b. Define the Objectives for a Solution

Menyimpulkan suatu tujuan untuk menyelesaikan solusi dan definisi masalah dan pengetahuan tentang kemungkin dan kelayakannya. Tujuan tesebut dapat bersifat kualitatif, misalnya deskripsi tentang bagaiman a artefak baru yang diharapkan mendukung solusi untuk masalah yang tidak ditangani. Objektif harus disimpulkan secara rasional dari spesifikasi masalah.

c. Design and Development

Tahap ini melakukan pembuatan artefak yang membangun metode, model, atau instansiasi y ang bersifat baru yang berasal dari sumber daya teknis, sosial, ataupun informasi.

\section{d. Demonstration}

Pada tahap ini memberikan gambaran dari penggunaan dari artefak yang sudah siap yang sesuai dengan den gan solusi yang ditawarkan. Proses dilakukan dengan melakukan eksperimen, simulasi, studi kasus, bukti, atau aktivitas lain yang sesuai dan keperluan sumber daya yang diperlukan sehingga lebih efektif dalam memberikan solusi dari permasalahan.

\section{e. Evaluation}

Tahap ini melakukan proses evaluasi dengan pengamatan dan pengukuran seberapa baik artefak yang digun ak an untuk menyelesaikan permasalahan. Hal ini dengan melakukan kegiatan membandingkan tujuan dari solusi untuk mengamati hasil yang aktual dari penggunaan artefak dalam demonstrasi. Proses yang dikerjakan membutuhkan 
pengetahuan tentang metrik yang relevan dan teknik menganalisa.

\section{f. Communication}

Pada Tahap ini dengan membicarakan masalah, artefak, utilitas dan pembaharuan, kekakuan desain, dan efektifitas untuk penulis dan penonton yang relevan bersifak profesional ketika telah sesuai

\section{Hasil dan Pembahasan}

\subsection{Analisis Sistem}

\section{a. Sistem Lama}

Pada sistem sebelumnya pemilik kebab hanya menawarkan dari mulut ke mulut sehingg sehingga penjualan kurang ramai ditambah pandemic saat ini.

b. Sistem Baru

Pada sistem baru penulis mengusulkan untuk pembuatan company profile sehingga penjualan lebih dikenal oleh banyak orang agar informasi produk dapat diupdate setiap saat.

\subsection{Analisis Sistem}

Analalisis sistem yang sedang berjalan dilakukan agar peneliti dapat mengetahui prosedur yang sedang berjalan sebelum melakukan pengembangan. Berikut adalah Flowchart yang sedang berjalan:

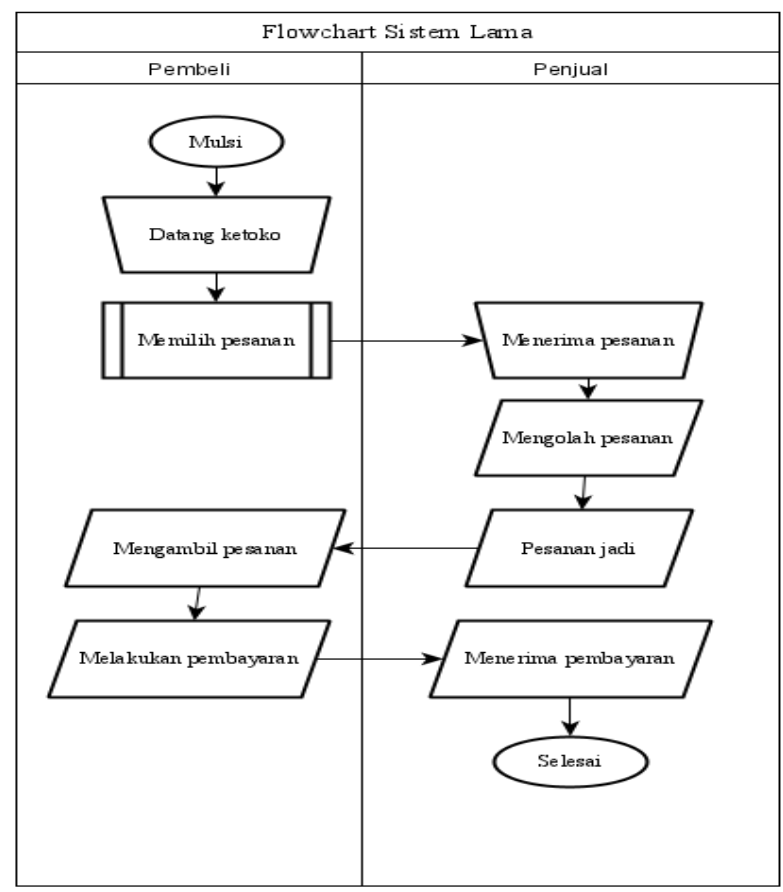

Gambar 2. Flowchart Sistem Berjalan

\subsection{ProsedurUsulan}

Berdasarsarkan analisis sistem yang sedang berjalan maka peneliti melakukan pengembangan sistem untuk mempermudah prosedur yang sedang berjalan. Berikut adalah flowchart sistem yang diusulan.: 


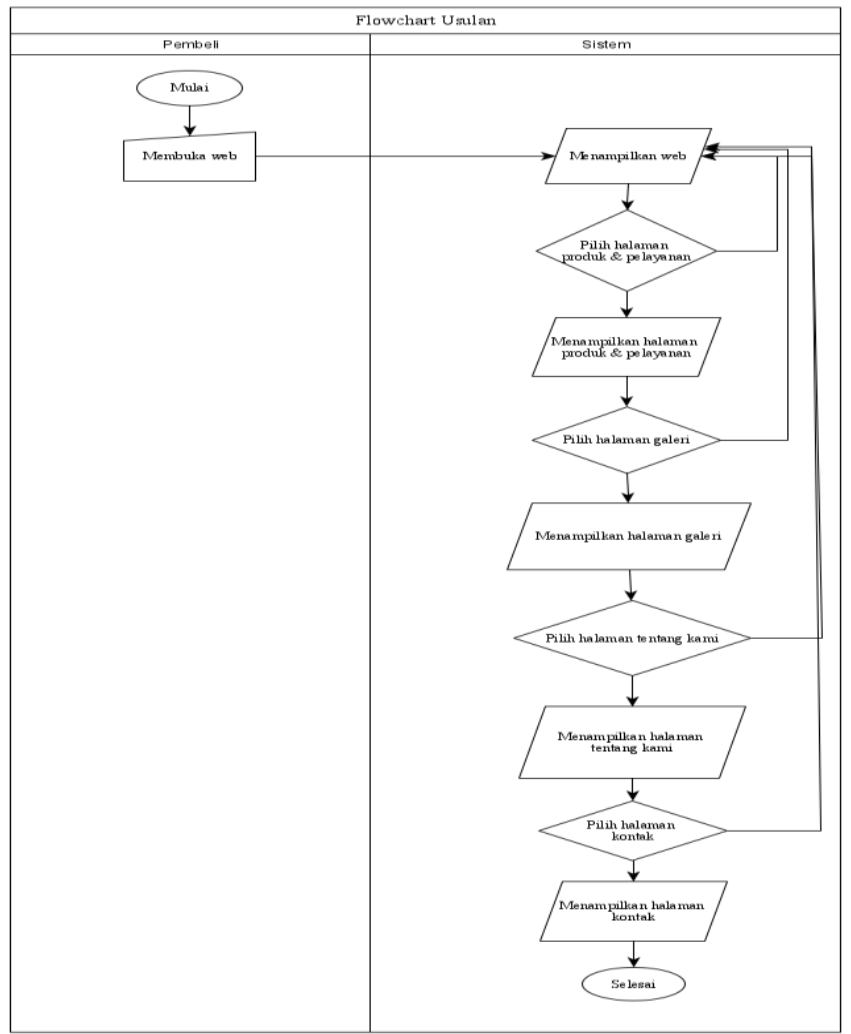

Gambar 3. Flowchart Sistem Yang Diusulkan

\subsection{Perancangan Sistem}

a. Use Case Diagram

Use case diagram merupakan pemodelan untuk menggambarkan kelakuan dari sistem yang dibuat dan mendeskripsikan sebuah interaksi antara satu atau lebih actor dengan sistem yang dibuat serta,digunakan untuk mengetahui fungsi apa saja yang ada didalam sebuah sistem dan siapa saja yang berhak menggunakan fungsi-fungsi tersebut (Hendini, 2016).

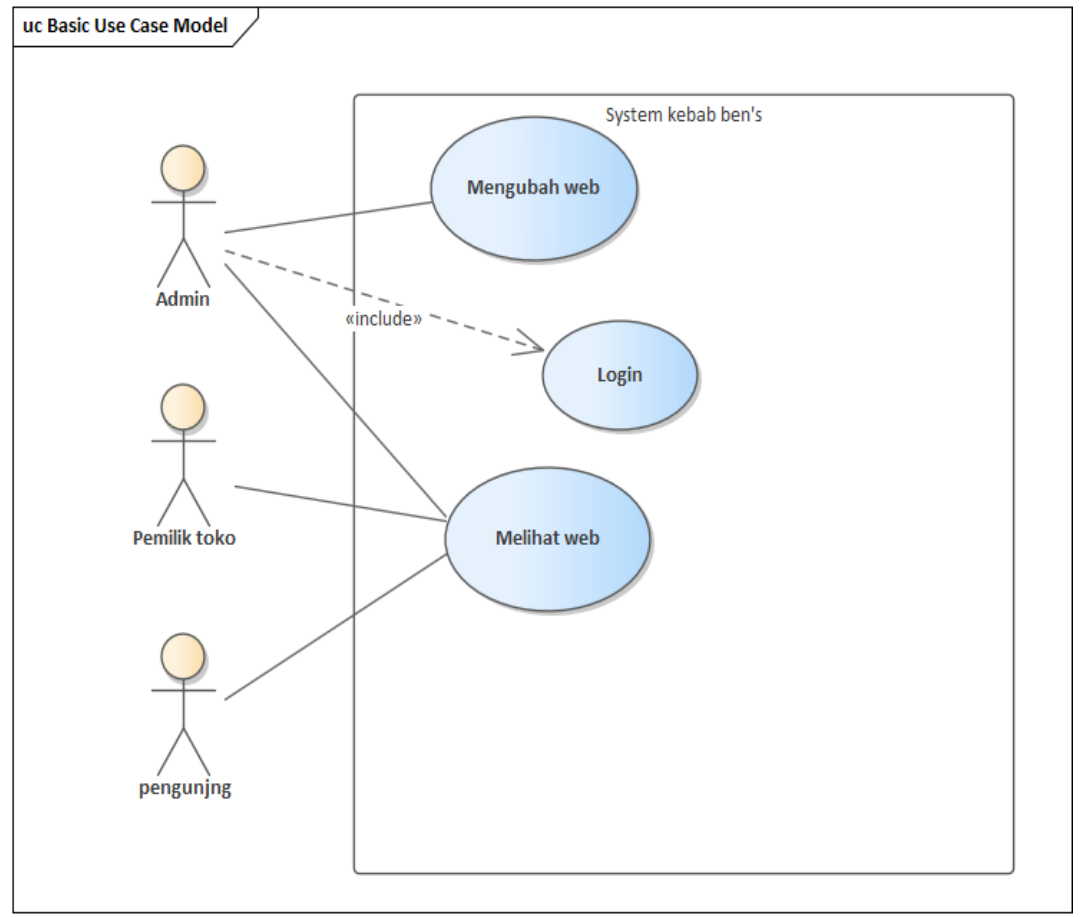

Gambar 4. Usecase System Kebab Ben's

Pada gambar diatas dijelaskan bahwa admin dapat login, mengubah web, dan melihat web dan pemilik toko hanya bisa login dan melihat web saja tidak bisa mengubah web, dan pengunjung hanya dapat melihat web saja. 
b. Activity Diagram

Activity diagram merupakan pemodelan yang menggambarkan sebuah sistem kerja dari sebuah objek atau sebuah sistem, sebuah activity diagram digambarkan dengan sebuah alur secara terstruktur proses kerja dari use case yang sedang diproses dari titik awal sampai titik akhir, setiap aktivitas digambarkan dengan notasi-notasi sesuai fungsinya (Aliman, 2021),

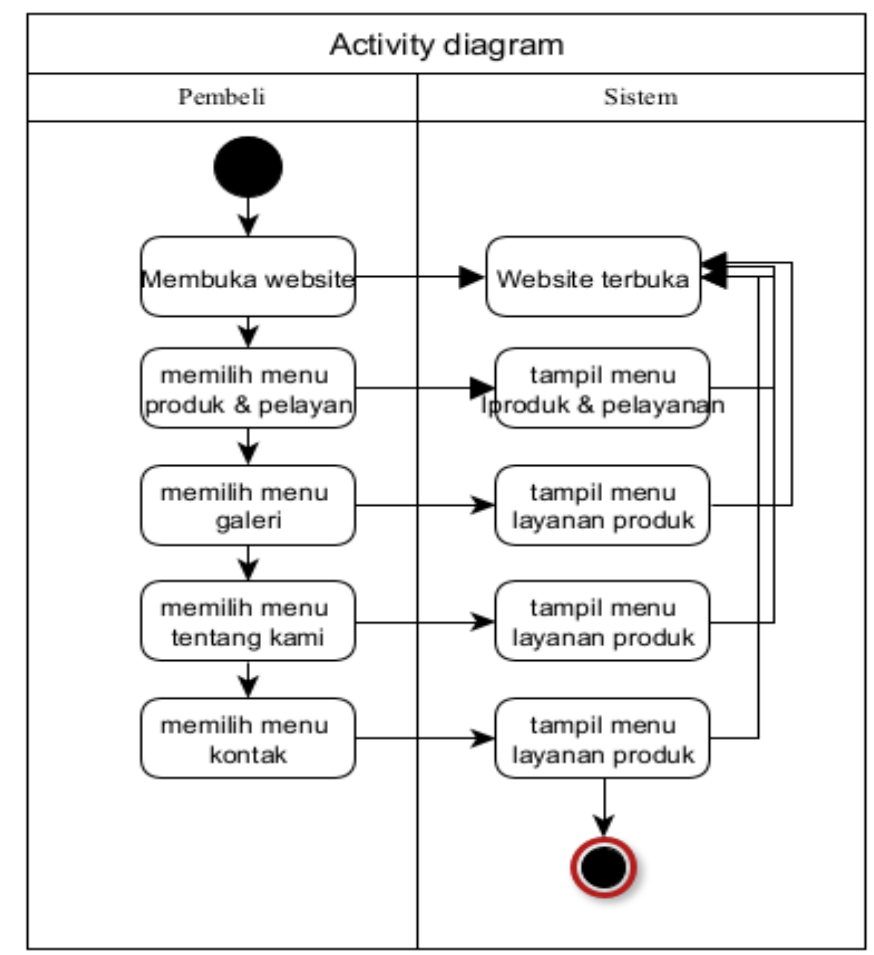

Gambar 5. Activity Diagram Pembeli

Pada gambar diatas dijelaskan alur activity diagram dari kegiatan pembelidapat membuka website tersebut, setelah website terbuka pembeli dapat melihat apa saja yang ada ditoko tersebut. Dan dapat membuka pada halaman-halaman yang tersedia dalam website tersebut sehingga dapat mengetahui apa saja yang ada didalamnya.

c. Squence Diagram

Sequence Diagram adalah diagram yang dibuat untuk mengetahui alur dari interaksi antar objek (Fitri Ayu \& Permatasari, 2018). Sequence diagram berfungsi untuk memberikan gambaran detail dari setiap use case diagram. 


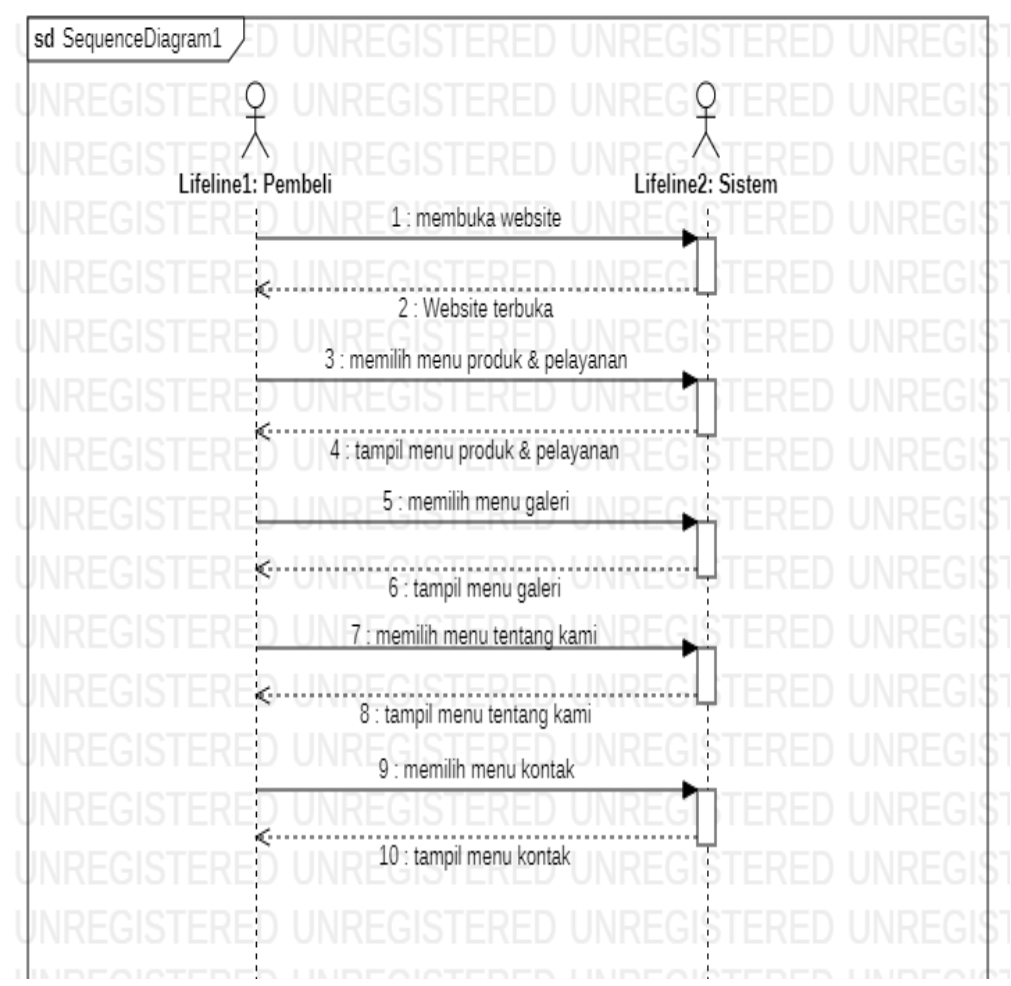

Gambar 6. Activity Diagram Pembeli

Pada gambar diatas dijelaskan squence diagram dari sistem yang dirancang untuk menghasil company profile kebab ben's maka awalan user akan membuka website company profile keb ab ben's, setelah website terbuka pembeli dapat memilih halaman yang mau dilihat.

\subsection{Implementasi Program}

Implementasi program dibawah ini berisi uraian seluruh layout website beserta metode penggunaanya dengan harapan pengguna baik admin serta user mudah mengerti terhadap menu-menu dalam web. Rancangannya sendiri dibuat sesederhana mungkin agar dimengerti oleh pengguna dan orang lain yang melihatnya guna memudahkan untuk mengakses suatu informasi yang ada didalam website tersebut.

a. Tampilan Halaman Beranda

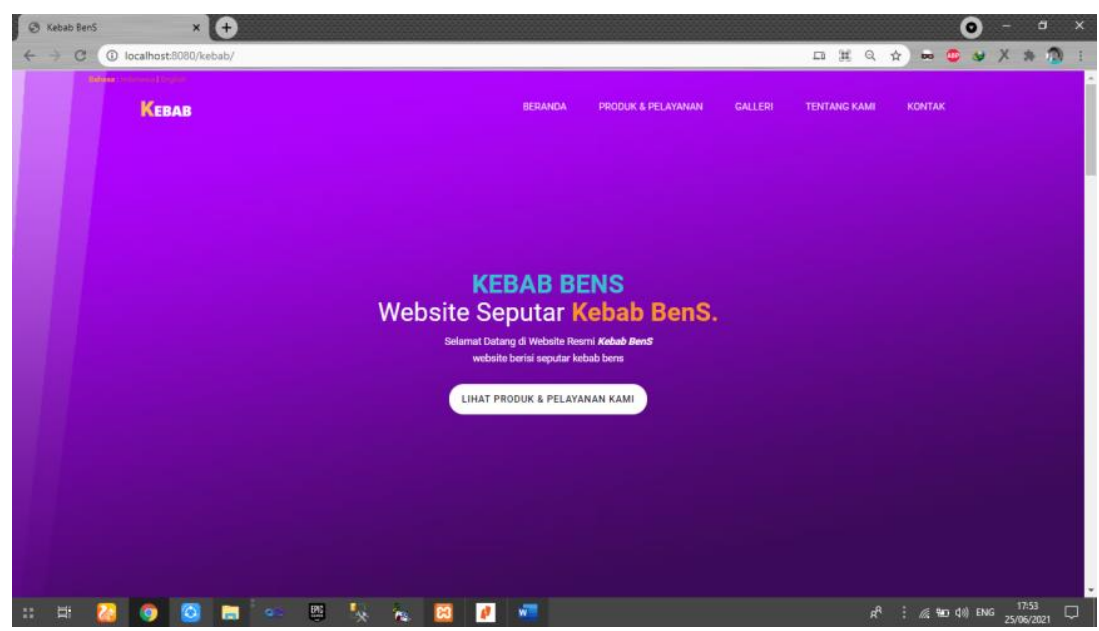

Gambar 7. Tampilan Menu Beranda

Keterangan:

Halaman Beranda dimana didalam form ini berisikan penjelasn tentang website company profile kebab ben's dan sebagai hiasan website.

b. Tampilan Halaman Produk 


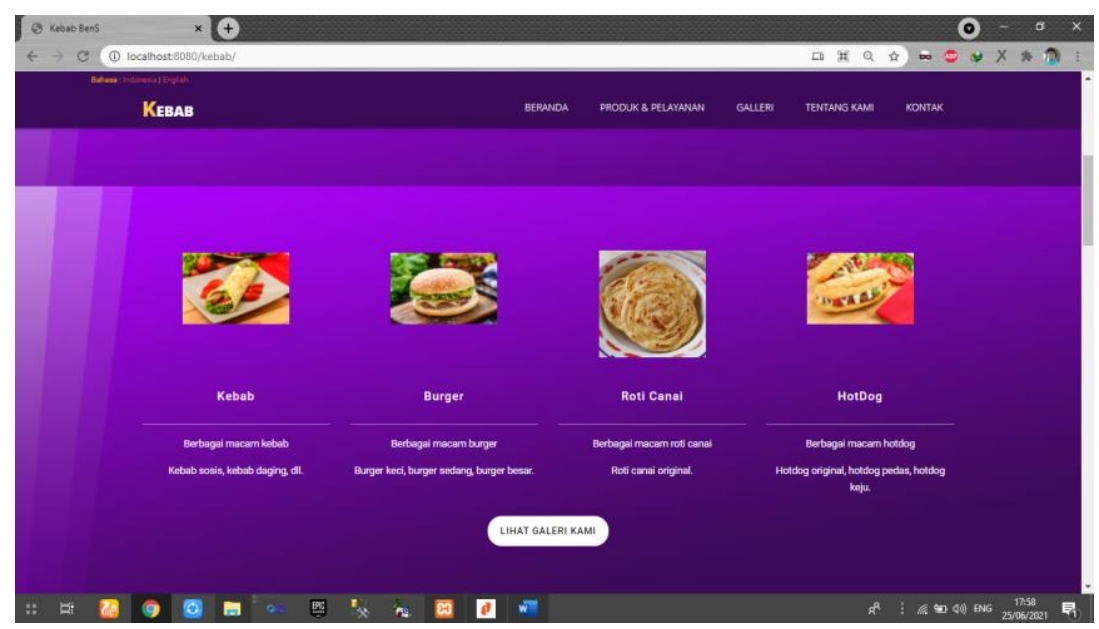

Gambar 8. Tampilan Produk

Keterangan:

Halaman produk yang dimana didalamnya berisikan apa saja yang dijual dan berbagai mac am rasa pada kebab ben's. Dimana pengguna dapat tahu apa saja yang dijual pada kebab tersebut agar udah memilih.

c. Tampilan Galeri

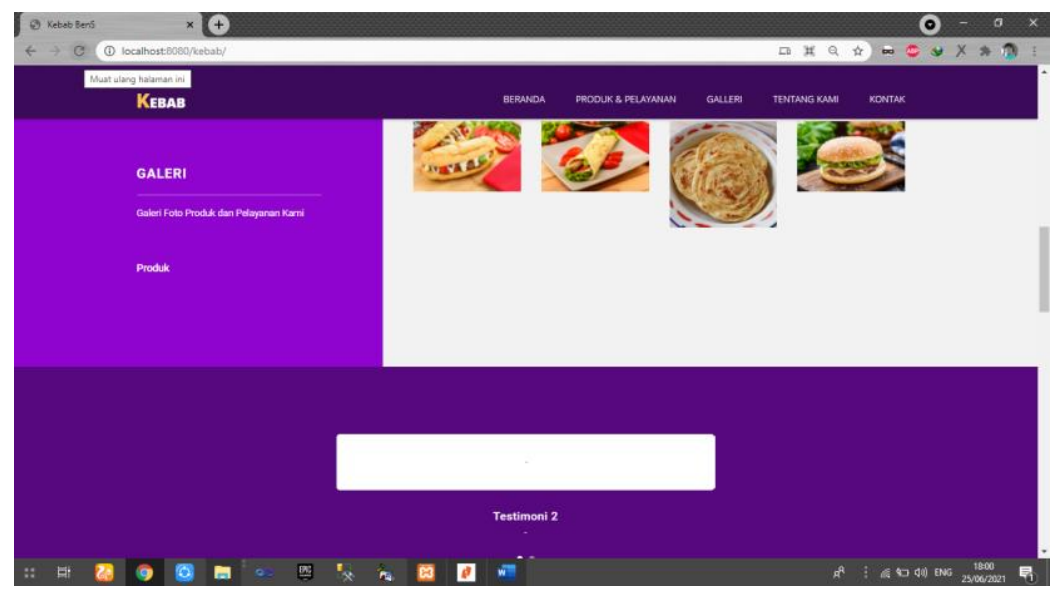

Gambar 9. Tampilan Galeri

Keterangan:

Halaman galeri dimana didalamnya terdapat beberapa contoh foto makanan yang dijual pada kebab ben's. Agar pengguna tau bahwa makananya akan seperti itu.

d. Tampilan tentang kami

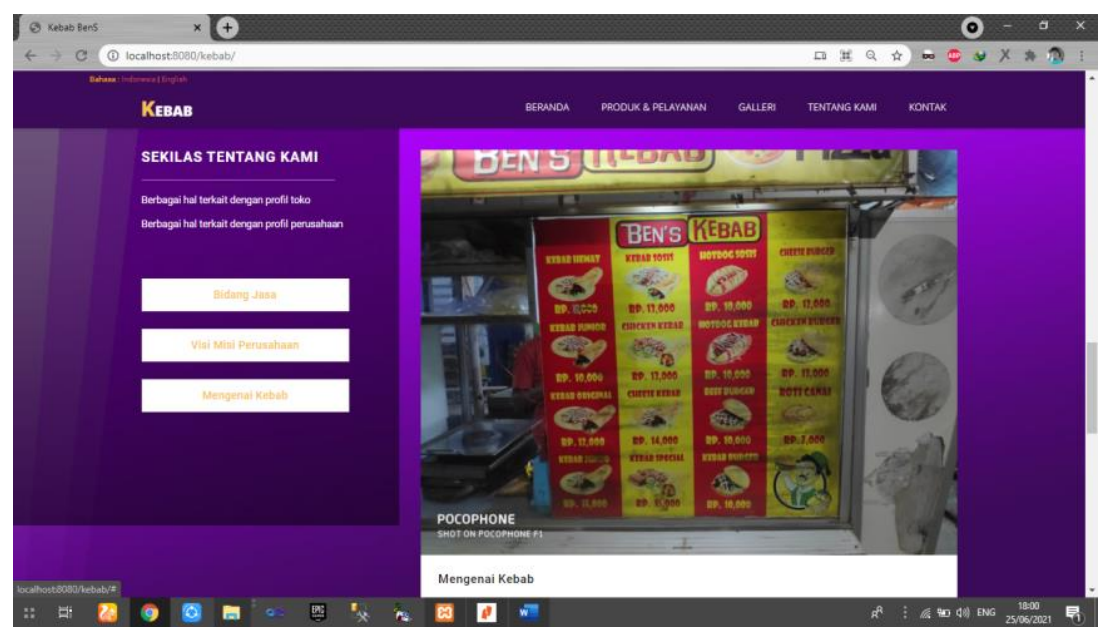

Gambar 10. Tampilan Tentang Kami

Keterangan: 
Halaman tentang kami berisi tentang penjelasan mengenai kebab dan visi misi pada kebab ben's yang dapat dilihat oleh pengunjung yang bisa dilihat pada form tersebut.

e. Tampilan Halaman Kontak

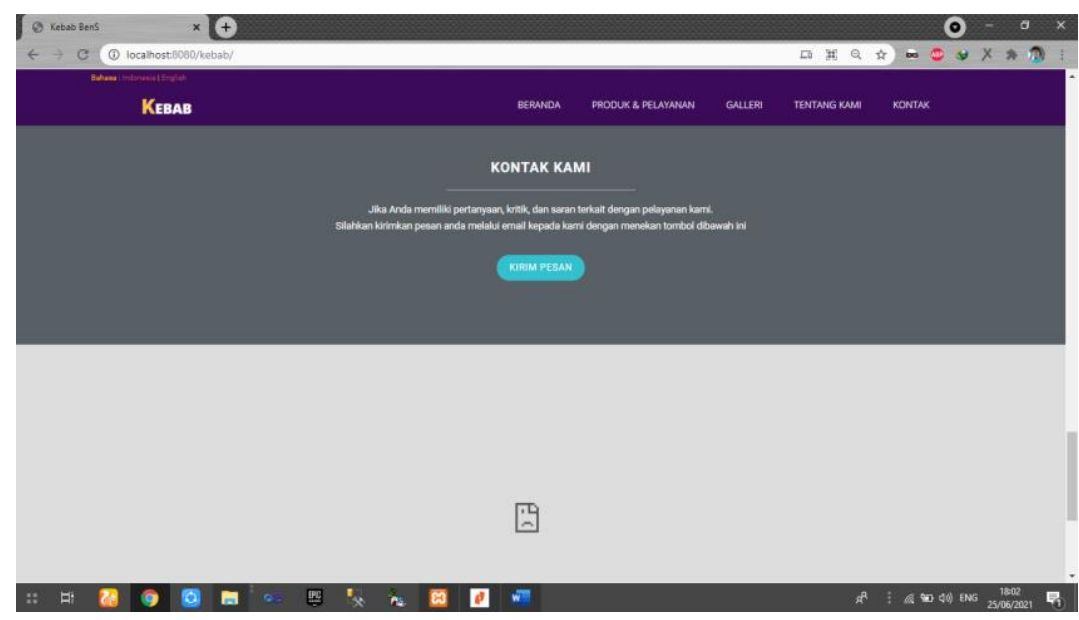

Gambar 11. Tampilan Kontak Kami

Keterangan:

Halaman kontak berisi tentang kritik dan saran yang dapat diisi oleh pengunjung

\subsection{Pengujian Aplikasi}

Black box testing merupakan pengujian kualitas perangkat lunak yang berfokus pada fungsionalitas perangkat lunak. Pengujian black box testing bertujuan untuk menemukan fungsi yang tidak benar, kesalahan antarmuka, kesalahan pada struktur data, kesalahan perfomansi, kesalahan inisialisasi dan terminasi (Setiyani, 2019). Berikut ini hasil pengujian website company profile kebab ben's menggunakan metode black box.

Tabel 1. Pengujian Aplikasi

\begin{tabular}{cllll}
\hline No & Uraian & Test Case & Hasil Pengujian & Kesimpulan \\
\hline 1 & Saat klik menu beranda & Klik menu beranda & Sesuai harapan & Valid \\
\hline 2 & $\begin{array}{l}\text { Saat klik menu produk dan } \\
\text { pelayanan }\end{array}$ & $\begin{array}{l}\text { Klik menu produk dan } \\
\text { pelayanan }\end{array}$ & Sesuai harapan & Valid \\
\hline 3 & Saat klik menu galeri & Klok menu galeri & Sesuai harapan & Valid \\
\hline 4 & Saat klik menu tentang kami & Klik menu tentang kami & Sesuai harapan & Valid \\
\hline 5 & Saat klik menu bidang jasa & Klik menu bidang jasa & Sesuai harapan & Valid \\
\hline 6 & $\begin{array}{l}\text { Saat klik menu visi misi } \\
\text { perusahaan }\end{array}$ & $\begin{array}{l}\text { Klik menu visi misi } \\
\text { perusahaan }\end{array}$ & Sesuai harapan & Valid \\
\hline 7 & $\begin{array}{l}\text { Saat klik menu mengenai } \\
\text { kebab }\end{array}$ & $\begin{array}{l}\text { Klik menu mengenai } \\
\text { kebab Sesuai harapan }\end{array}$ & Valid \\
\hline 8 & Saat klik menu kontak & Klik menu kontak & Sesuai harapan & Valid \\
\hline 9 & Saat klik menu kirimpesan & Klik menu kirim pesan & Sesuai harapn & Valid \\
\hline
\end{tabular}

\section{Kesimpulan \& Saran}

\subsection{Kesimpulan}

Kesimpulan dari penelitian ini adalah membangun perancangan company profile pada kebab ben's sehingga dengan adanya website disaat pandemic orang dapat mengetahui apa saja yang dijual oleh kebab ben's dan dapat diketahui banyak orang. Dengan adanya penelitian ini dapat membantu penjauan pada kebab ben's agar kebab ben' bisa lebih maju dengan adanya website ini.

\subsection{Saran}

Adapun saran yang dapat diberika pada website agar dapat hasil yang maksimal. Maka saran yang diberikan untuk pengembangan website ini adalah sebagai berikut:

a. Website ini masih memungkinkan transaksi secara online produk untuk dikebangkan

b. Website ini bisa digunakan untuk penyimpana data dengan database dan halam baru pada admin y ang bisa dikembangkan. 


\section{References}

Aliman, W. (2021). PERANCANGAN PERANGKAT LUNAK UNTUK MENGGAMBAR DIAGRAM BERBASIS ANDROID. Syntax Literate: Jurnal Ilmiah Indonesia, 6(6), 6.

Anggriana, R., Qomariah, N., \& Santoso, B. (2017). Pengaruh Harga, Promosi, Kualitas Layanan Terhadap Kepuas an Pelanggan Jasa Ojek Online “Om-Jek” Jember. JSMBI( Jurnal Sains Manajemen Dan Bisnis Indonesia ), 7(2), 137156.

Fernando, E., Surjandy, Meyliana, \& Siagian, P. (2020). Desain Sistem Pengenalan Varietas Bibit Tanaman Kelapa Sawit dengan Pendekatan Design Science Research Methodology (DSRM). Jurnal Teknologi Informasi Dan Ilmu Komputer, 7(2), 249. https://doi.org/10.25126/jtiik.2020721456

Fitri Ayu, \& Permatasari, N. (2018). Perancangan Sistem Informasi Pengolahan Data PKL pada Divisi Humas PT Pegadaian. Jurnal Infra Tech, 2(2), 12-26. http://journal.amikmahaputra.ac.id/index.php/JIT/article/download/33/25

Hasyim, N., Hidayah, N. A., \& Latisuro, S. W. (2014). Rancang Bangun Sistem Informasi Koperasi Berbasis Web pada Koperasi Warga Baru MTs N 17 Jakarta. STUDIA INFORMATIKA: JURNAL SISTEM INFORMASI, 7(2), 53-63.

Hendini, A. (2016). PEMODELAN UML SISTEM INFORMASI MONITORING PENJUALAN DAN STOK BARANG (STUDI KASUS: DISTRO ZHEZHA PONTIANAK). JURNAL KHATULISTIWA INFORMATIKA, IV(2). https://doi.org/10.2135/cropsci1983.0011183x002300020002x

Herman, N., \& Janah, N. Z. (2020). Rancang Bangun Company Profile E-Life Solutions Plt Berbasis Web Sebagai Corporate Branding. Journal of Applied Multimedia and Networking, 4(2), 16-26. https://doi.org/10.30871/jamn.v4i2.2206

Hidayat, A., \& Faisal. (2019). Rancang Bangun Sistem Informasi Penyewaan Lahan Parkir Berbasis Web GIS. Jurnal Sistem Informasi Dan Sains Teknologi, 1(1), 1-9.

Juliany, I. K., Salamuddin, M., \& Dewi, Y. K. (2018). Perancangan Sistem Informasi E-Marketplace Bank Sampah Berbasis Web. Seminar Nasional Teknologi Informasi Dan Multimedia 2018, 19-24. https://doi.org/10.1111/j.13652621.2009.02155.x

Kristia Akmal, R., \& Jaenudin, J. (2018). Perancangan Company Profile Bpm Bidan Wita Utami Awaliyah, S.St Berbasis Web. Inova-Tif, 1(2), 125.https://doi.org/10.32832/inova-tif.v1i2.5500

Munandar, A., \& Suryadi, L. (2020). Pemodelan Sistem Informasi Penjualan Barang Pada CV. Clever Kids Dengan Menggunakan Metodologi Berorientasi Objek. Jurnal Idealis, 3(1), 227-233.

Neisia, T. C., Kalangi, J. A. . F., \& Walangitan, O. (2018). Pengaruh Harga Terhadap Penjualan Produk Motor Yamaha Mio Pada PT. Hasjrat Abadi Outlet Karombasan Manado. Jurnal Administrasi Bisnis, 6(003). https://doi.org/10.35797/jab.6.003.2018.20284.

Setiyani, L. (2019). Pengujian Sistem Informasi Inventory Pada Perusahaan Distributor Farmasi Menggu nakan Meto de Black Box Testing. Techno Xplore: Jurnal Ilmu Komputer Dan Teknologi Informasi, 4(1), 1-9. https://doi.org/10.36805/technoxplore.v4i1.539

Suwarno, \& Sanjaya, T. (2020). Perancangan dan Implementasi Company Profile pada PT. Ekadi Trisakti Mas Sebagai Media Promosi Berbasis Website. Conference on Business, Social Sciences and Technology, 1(1), 46-78. http://repository.uib.ac.id/id/eprint/2668

Tabrani, M., \& Pudjiarti, E. (2017). PENERAPAN METODE WATERFALL PADA SISTEM INFORMASI INVENTORI PT. PANGAN SEHAT SEJAHTERA. Jurnal Inkofar, 1(2), 189-196. http://www.politeknikmeta.ac.id/meta/ojs/

Tendra, G., Aminoto, \& Mulyati, R. (2018). Teknologi Website Untuk Pengenalan Lingkungan Serta Eksplorasi Desa Air Emas Kecamatan Ukui Kabupaten Pelalawan. Jaringan Sistem Informasi Robotik, 2(01), 81-85.

Tisnawati, A., \& Baharuddin. (2016). Sistem Periklanan Dan Pencarian Rumah Kos Online Berbasis Web. JURNAL SISTEM INFORMASI DAN TEKNIK KOMPUTER CATUR SAKTI, $1(1), \quad 38-44$. https://doi.org/10.51876/simtek.v1i1.6

Yusti, I. (2016). Sistem Informasi Manajemen Surat Berbasis Php Dan Mysql Di Institut Seni Indonesia Padangpanjang. Jurnal Sains Dan Teknologi, 16(1). https://doi.org/10.36275/stsp.v16i1.53

Zufria, I., \& Azhari, M. H. (2017). Web-Based Applications in Calculation of Family Heritage ( Science of Faroidh ). QUERY : Jurnal Sistem Informasi, 01(01), 50-60. http://journal.unnes.ac.id/sju/index.php/piwulang 